\title{
"If You Have No Money, You Might Die": A Qualitative Study of Sociocultural and Health System Barriers to Care for Decedent Febrile Inpatients in Northern Tanzania
}

\author{
Michael E. Snavely, ${ }^{1 \star}$ Martha Oshosen, ${ }^{2}$ Elizabeth F. Msoka, ${ }^{2,3}$ Francis P. Karia, ${ }^{2,4}$ Michael J. Maze, ${ }^{5}$ Lauren S. Blum, ${ }^{6}$ \\ Matthew P. Rubach, ${ }^{2,7,8}$ Blandina T. Mmbaga, ${ }^{2,3,9}$ Venance P. Maro, ${ }^{2,9}$ John A. Crump, ${ }^{1,2,5}$ and Charles Muiruri ${ }^{1,2,10}$ \\ ${ }^{1}$ Duke Global Health Institute, Duke University, Durham, North Carolina; ${ }^{2}$ Kilimanjaro Christian Medical Centre, Moshi, Tanzania; ${ }^{3}$ Kilimanjaro \\ Clinical Research Institute, Moshi, Tanzania; ${ }^{4}$ Duke Office of Clinical Research, Duke University School of Medicine, Durham, North Carolina; \\ ${ }^{5}$ Centre for International Health, University of Otago, Dunedin, New Zealand; ${ }^{6}$ Duke University, Durham, North Carolina; ${ }^{7}$ Division of Infectious \\ Diseases and International Health, Duke University Medical Center, Durham, North Carolina; ${ }^{8}$ Programme in Emerging Infectious Diseases, Duke- \\ National University of Singapore, Singapore, Singapore; ${ }^{9}$ Kilimanjaro Christian Medical University College, Moshi, Tanzania; ${ }^{10}$ Department of \\ Population Health, Duke University, Durham, North Carolina
}

\begin{abstract}
Infectious diseases are a leading cause of mortality in low- and middle-income countries (LMICs) despite effective treatments. To study the sociocultural and health system barriers to care, we conducted a qualitative social autopsy study of patients who died from febrile illness in northern Tanzania. From December 2016 through July 2017, we conducted in-depth interviews in Arusha and Kilimanjaro regions with a purposive sample of 20 family members of patients who had died at two regional referral hospitals. Of the deceased patients included in this study, $14(70 \%)$ were adults and 10 (50\%) were female. Patients identified their religion as Catholic (12, 60\%), Lutheran (six, 30\%), and Muslim (two, 10\%), and their ethnicity as Chagga (14, 70\%) and Sambaa (two, 10\%), among others. Family members reported both barriers to and facilitators of receiving health care. Barriers included a perceived lack of capacity of local health facilities, transportation barriers, and a lack of formal referrals to higher levels of care. Family members also reported the cost of health care as a barrier. However, one facilitator of care was access to financial resources via families' social networks-a phenomenon we refer to as social capital. Another facilitator of care was families' proactive engagement with the health system. Our results suggest that further investment in lower level health facilities may improve care-seeking and referral patterns and that future research into the role of social capital is needed to fully understand the effect of socioeconomic factors on healthcare utilization in LMICs.
\end{abstract}

\section{INTRODUCTION}

Infectious diseases cause a substantial share of mortality in low- and middle-income countries (LMICs) despite clinical management guidelines and effective antimicrobials. ${ }^{1-3}$ In Tanzania, in particular, $44 \%$ of deaths were caused by infectious diseases as of 2015., 4 To help explain elevated mortality rates due to infectious diseases, researchers in LMICs have used a social autopsy method to describe the social, cultural, and health system barriers to care experienced during a fatal illness. ${ }^{6-8}$ The social autopsy method most commonly consists of structured, retrospective interviews yielding quantitative data, and these interviews are usually conducted weeks to months after a death in the family. ${ }^{9} \mathrm{~A}$ systematic review in 2017 described the common themes in social autopsy studies as 1) the recognition of severe illness by family members but inconsistency in subsequent careseeking, 2) the cost of transport and healthcare expenses as barriers to care, and 3) low quality of health care provided. ${ }^{10}$

Social autopsy interviews conducted weeks after a death are prone to recall bias. To improve on this framework, we recently published a prospective study wherein patients were interviewed during a febrile illness. ${ }^{11}$ These antemortem surveys reduced recall bias and allowed for inclusion of a matched control group of patients who did not go on to die from their febrile illness. Key findings such as presenting to a health facility $>24$ hours after the start of a severe illness, transport time $>1$ hour, and visiting $>2$ facilities during a given illness were significantly associated with mortality among febrile inpatients. ${ }^{11}$ However, these quantitative findings lack

*Address correspondence to Michael E. Snavely, Department of Family and Community Medicine, 995 Potrero Ave., San Francisco, CA 94110. E-mail: michael.snavely@ucsf.edu the context of unknown or unmeasured confounders that may mediate the relationship between mortality and the delays described. For example, patient transport times may be due to long distances, poorly maintained roads, or lack of affordable transit options, and interventions would look different in each case.

Qualitative methods such as open-ended interviews are an established strategy to explore and elaborate on the nuances and potential confounders in quantitative data. ${ }^{12-14}$ Few social autopsy studies have used qualitative methods to elaborate on the growing body of quantitative findings. In fact, a recent systematic review of social autopsy literature concluded that the field was lacking the qualitative narratives necessary to reconcile inconsistent results such as families not seeking care despite the recognition of a severe symptom. ${ }^{10}$ Combining qualitative and quantitative methods in global health provides an epistemological nuance that reflects the complexity of patients' lived experiences. Exploring this nuance can be critical to identify appropriate health interventions. $^{13,15}$ To provide further context to our earlier quantitative, prospective study, we conducted in-depth interviews among a purposive sample of families of patients who had recently died of fever. Our objective was to elaborate and triangulate the salient sociocultural and health system barriers during febrile illness in northern Tanzania.

\section{MATERIALS AND METHODS}

Study setting and population. The study was carried out from December 7, 2016 through July 10, 2017 in northern Tanzania. The main ethnic groups in Kilimanjaro region are Chagga, Pare, and Sambaa. The population is predominantly composed of Catholic, Muslim, and Lutheran religious groups. Participants were recruited in Moshi, Tanzania, from 
one of two large referral hospitals: Kilimanjaro Christian Medical Centre (KCMC) or Mawenzi Regional Referral Hospital (MRRH). Interviews were then conducted in both urban and rural wards across the Arusha and Kilimanjaro regions.

The health system in Tanzania includes government and private health facilities, pharmacies and drug retailers, and a variety of traditional or religious healers. The government system has a pyramidal structure and comprises three functional levels: district, regional, and referral hospital (e.g., $\mathrm{KCMC}$ or $\mathrm{MRRH}$ ). At the district level, dispensaries, health centers, and district hospitals provide primary health services and refer to secondary, regional hospitals when needed. Larger referral hospitals exist to provide tertiary care based on referrals from lower levels of care. ${ }^{16}$

Sampling frame. Participants were part of a larger qualitative study focusing on acceptability of autopsy in Tanzania (F. P. Karia, et al., unpublished data). A purposive sample of 20 respondents was recruited among adult caregivers of patients who had recently died either on the internal medicine or pediatric wards of $\mathrm{KCMC}$ or $\mathrm{MRRH}$. The caregiver contacted for participation was the family member identified in the immediate postmortem period as best able and willing to respond to questions related to the patient's illness, care-seeking behaviors, and care received in the health facilities. The present study was limited to the subset of participants whose relative had died of a febrile illness. The definition of febrile illness was a history of fever in the past 72 hours; tympanic, rectal, or oral temperature of $\geq 38.0^{\circ} \mathrm{C}$ at admission; or axillary temperature of $>37.5^{\circ} \mathrm{C}$ at admission. These inclusion criteria match those of the quantitative social biopsy study to which the qualitative data presented here are a corollary. ${ }^{11}$

Data collection. The interview guide (Supplemental File) was designed to further explore the sociocultural and health system barriers quantitatively shown to be associated with mortality. ${ }^{11}$ Two researchers in public health (M. O.) and nursing (E. F. M.), both with experience in qualitative data collection, conducted the interviews. Open-ended questions on barriers to access, cost, and quality of healthcare services rendered to the deceased were explored. Eligible families were either approached in the hospital or, if they had already left the hospital, by telephone to identify a convenient time to schedule an interview. Interviews were carried out 3-10 days after the death either in a private location in the hospital such as a medical office, in the home of the family of the deceased, or if requested by the respondent, in a motor vehicle. Interviews lasted no longer than 45 minutes. In-depth interviews were conducted in Kiswahili, digitally recorded, de-identified, and professionally transcribed and translated into English. Recruitment continued to obtain the purposive sample of 20 patients.

Data analysis. All interview transcripts were transferred to NVivo 11 (QSR International, Melbourne, Australia) for analysis. To characterize our study sample, we collected the deceaseds' age, gender, religion, ethnic background, and hospital where they died. We also collected the interview respondents' age, gender, religion, ethnic background, city, number of years of formal education, and relationship to the deceased. Qualitative analysis involved both deductive and inductive processes. The deductive step used salient themes from our previous quantitative work, ${ }^{11}$ and the inductive step identified emergent themes. Two independent coders (C. M. and M. E. S.) applied the deductive coding template to the first five interview transcripts. The initial template was then revised, and emergent thematic codes were added in a hierarchical fashion to create a final coding template that was applied to all transcripts, including the original five. Two authors (C. M. and M. E. S.) coded all transcripts. Coders checked for consistency in applying the code list and definitions to the transcribed interviews through discussion and reconciliation. A third author (M. R.) reviewed discrepancies between coders.

Ethical procedures. The study protocol was reviewed and ethical approval granted by the Institutional Review Boards at the KCMC Research Ethics Committee, Moshi, Tanzania, and the Duke University Health System Institutional Review Board. Signed informed consent was obtained from all the in-depth interview respondents.

\section{RESULTS}

Demographics. We conducted 20 interviews with family members of patients who had died with a febrile illness at either KCMC or MRRH. Demographic characteristics of the decedents and the interview respondents are listed in Table 1. Of the deceased, 10 (50\%) were female, with a median (range) age of $41(<1,97)$ years. Twelve $(60 \%)$ decedents were Catholic, six (30\%) Lutheran, and two (10\%) Muslim. Of decedents, 14 (70\%) were from the Chagga ethnic group, two (10\%) were of Sambaa ethnicity, and the remainder from Pare, Meru, Nyaturu, and Zigua ethnic groups. Among interview respondents, five (25\%) were female. Otherwise, the religion and ethnic identities of respondents were the same as those of the deceased family member. The median (range) duration of formal education of respondents was seven (7-16) years. The main themes in our deductive analysis were barriers to presenting to a health facility and barriers within the health system. The emerging theme from our inductive analysis was facilitators of receiving care, which included the subthemes of proactive families and social capital (Table 2). Social capital refers to the resources family members accessed via their social network. ${ }^{17}$ More specifically, our results describe the phenomenon of bonding social capital, which refers to social connections or the sharing of resources among a tightly knit but informal social network, such as family or close friends. ${ }^{18}$ However, the concept of social capital is debated theoretically, and more consideration of where our results fit in the literature is given in the discussion.

Barriers to presenting to a health facility. The most common barrier participants reported was having to bypass their local health facility because of a perceived lack of capacity, such as a shortage of medicine or equipment. This perception led participants to bypass local facilities, effectively referring themselves to larger hospitals.

Perceived lack of capacity and self-referrals. We defined a perceived lack of capacity as the belief among respondents that a given health facility did not have the medicines or equipment to meet the needs of a family member's illness. Participants perceived a lack of capacity among first-level health facilities and rural hospitals, leading families to travel longer distances to present to care at larger central hospitals. For example, a 43-year-old Sambaa father reported, "I told [my wife] to bring the child to Moshi urban hospitals because rural hospitals have failed. So the child didn't come here by transfer, we just came on our own without a referral." 
TABLE 1

Demographic characteristics of decedents and interview respondents during qualitative social autopsy study, northern Tanzania, 2016-2017

\begin{tabular}{|c|c|c|}
\hline & Decedents & $\begin{array}{l}\text { Primary interview } \\
\text { respondents }\end{array}$ \\
\hline Characteristic & $n=20, \mathrm{n}(\%)$ & $n=20, \mathrm{n}(\%)$ \\
\hline \multicolumn{3}{|l|}{ Age (years) } \\
\hline$<18$ & $6(30)$ & $0(0)$ \\
\hline $18-39$ & $4(20)$ & $4(20)$ \\
\hline $40-59$ & $4(20)$ & $9(45)$ \\
\hline $60-79$ & $3(15)$ & 7 (35) \\
\hline$>79$ & $3(15)$ & $0(0)$ \\
\hline \multicolumn{3}{|l|}{ Gender } \\
\hline Female & $10(50)$ & $5(25)$ \\
\hline \multicolumn{3}{|l|}{ Ethnic group } \\
\hline Chagga & $14(70)$ & $14(70)$ \\
\hline Sambaa & $2(10)$ & $2(10)$ \\
\hline Pare & $1(5)$ & $1(5)$ \\
\hline Meru & $1(5)$ & $1(5)$ \\
\hline Nyaturu & $1(5)$ & $1(5)$ \\
\hline Zigua & $1(5)$ & $1(5)$ \\
\hline \multicolumn{3}{|l|}{ Religion } \\
\hline Catholic & $12(60)$ & $12(60)$ \\
\hline Lutheran & $6(30)$ & $6(30)$ \\
\hline Muslim & $2(10)$ & $2(10)$ \\
\hline \multicolumn{3}{|l|}{ Hospital at time of death } \\
\hline Kilimanjaro Christian Medical Center & $14(70)$ & N/A \\
\hline Mawenzi Regional Referral Hospital & $6(30)$ & - \\
\hline \multicolumn{3}{|l|}{ Respondent home } \\
\hline Urban & $\mathrm{N} / \mathrm{A}$ & $10(50)$ \\
\hline Rural & - & $8(40)$ \\
\hline Mixed & - & $2(10)$ \\
\hline \multicolumn{3}{|l|}{ Respondent years of schooling } \\
\hline$<8$ & $\mathrm{~N} / \mathrm{A}$ & $11(55)$ \\
\hline $8-12$ & - & $6(30)$ \\
\hline$>12$ & - & $3(15)$ \\
\hline
\end{tabular}

In another example, a 78-year-old Chagga man reported that while caring for his son, "the medicines to treat the patient were not available at Machame [a rural hospital]." He went on to explain that his family "[took] the patient to KCMC because the medicines were not available at Machame Hospital."

Another respondent, a 67-year-old Meru man described a self-referral for his now-deceased niece: "What made us decide that way was [that] the deceased had [a] problem with her chest, and the district hospital was the only hospital with [an] $\mathrm{X}$ ray machine [that] can show the problem in the chest. That test is not available in the [more remote] health facilities."

Transport barriers. Several respondents described the logistics of transportation as a barrier to presenting to a health facility. A 34-year-old Chagga man who lost his infant son explained, "the child's condition suddenly changed. However, because I was working away from home that day, my wife contacted her brother in law who lived nearby and had a car. Unfortunately, he was not home so she couldn't get help and she did not have another option," until "he arrived home at 5 AM."

Another respondent, a 78-year-old Chagga man who was caring for his son, described presenting to a health facility closer to home, even though the child's illness eventually required referral to KCMC. This was because "to Machame hospital ... you will pay only 300 Tanzanian shillings (TZS) [0.14 USD in 2016] for public transport and you will be able to reach your destination, but you will use 4000 TZS [1.84 USD in 2016] to go ... to KCMC." However, when the child was referred to KCMC, the father "went to the hospital and ... was asked to pay for ambulance charges [totaling] 45,000 TZS [20.72 USD in 2016] ... [but I] did not have the money to pay for the ambulance, so [I] came home and struggled to get the money."

Distance was also a barrier, as a 57-year-old Chagga woman who lost her mother explained, "reaching the hospital was a problem because of distance. ... My mother was very old [and so] sitting in the car ... was a big problem .... We wish ... there was a close by health care center [so] we could send her there. ... Even the care we started to provide her at home earlier on, it was because of the distance between home and the health [facility]."

Barriers within the health system. Barriers to receiving health care were not limited to the time spent deciding to present to a health facility and during transport. Participants also reported barriers that arose within the health system after they presented to a facility. These barriers included a lack of formal referrals and the cost of receiving health care.

Lack of formal referrals. When families did seek care at smaller or more remote health facilities, they often did not

TABLE 2

Main themes arising during qualitative social autopsy study, 2016-2017, in northern Tanzania

\begin{tabular}{|c|c|c|}
\hline Theme & Subtheme & Key findings \\
\hline \multirow[t]{2}{*}{ Barriers to presenting to a health facility } & $\begin{array}{l}\text { Perceived lack of capacity } \\
\text { and self-referrals }\end{array}$ & $\begin{array}{l}\text { The perception that local health facilities lacked adequate supplies or staff } \\
\text { influenced when and where participants presented to care. } \\
\text { Families often bypassed the closest facility, effectively referring } \\
\text { themselves to higher levels of care. }\end{array}$ \\
\hline & Transport barriers & $\begin{array}{l}\text { Logistics, cost, and long distances to the nearest health facility were all } \\
\text { reported as barriers. }\end{array}$ \\
\hline \multirow[t]{2}{*}{ Barriers within the health system } & Lack of formal referrals & $\begin{array}{l}\text { Families were not consistently referred to a higher level of care for severe } \\
\text { illnesses. } \\
\text { This led to delays, as families had to visit several facilities and often did not } \\
\text { have the necessary referral letters. }\end{array}$ \\
\hline & Cost barriers & $\begin{array}{l}\text { Many families reported that not being able to afford the costs of care put } \\
\text { patients at risk of dying. }\end{array}$ \\
\hline \multirow[t]{3}{*}{ Facilitators of receiving care } & Proactive families & $\begin{array}{l}\text { Participants recognized symptoms that required medical care and } \\
\text { proactively sought treatment. }\end{array}$ \\
\hline & Social capital & $\begin{array}{l}\text { Families frequently accessed financial assistance from friends and family } \\
\text { to pay for health care. }\end{array}$ \\
\hline & & This social capital mediated the impact of cost barriers. \\
\hline
\end{tabular}


receive a referral to a higher level of care despite the presence of signs of severe illness. For example, a 29-year-old Chagga woman described the lack of referral for her 2-month-old son with high fever:

The child's temperature was still rising; I decided to return to the clinic where I had come from. I met a Dr. to whom I explained about the body temperature of my child. ... He wrote me a prescription for ... paracetamol; ... however, there was no improvement. ... After a while, the temperature was [still] high, and again after some hours I gave him another medicine but still the temperature was high ... After sometime in the hospital, the same Dr. came with an injection ... to reduce the body temperature completely and he assured me that I should not worry. After the injection, I stayed there in the [clinic] and still the body temperature was high. The Dr. decided to take a piece of cloth and gave it to me so that I may do sponging and after that exercise the body temperature reduced, then the Dr. told me to go home ... This is because in that clinic they never hospitalize patients.

Subsequently, at home, the mother said, "the whole night I couldn't sleep. The child was crying and so I was awake taking care of him, as he was ... convulsing." The child continued to convulse as he was rushed to a larger hospital that immediately transferred him to KCMC, where he died within hours of arrival.

In another example, a 69-year-old Chagga man described how his family made their own decision to seek a higher level of care: "When you take the patient to the hospital and you don't see improvement, obviously you will be the one to take another step even without being told. We consulted each other."

The lack of formal referrals not only caused families to selfrefer but also led to delays in care, as self-referrals were met with requests for referral letters at the larger hospitals. Respondents described a system in which higher level facilities expected formal referrals but that those referrals were inconsistently given, even when signs of severe illness were present. For example, a 50-year-old Chagga man explained his experience in taking care of his grandmother: "But what I have found in Mawenzi Hospital. . . you have to have a referral. So when you go there with your patient and if you didn't start from the health center in the place where you live ... they can tell you 'take her back to the home health center and start from there."”

Cost barriers. Several respondents suggested that their deceased relative may have survived if it were not for cost barriers, as the 36-year-old Nyaturu man who lost his niece said, "it's a lot of money that we cannot get ... at once. This was the biggest challenge we had as family ... I am sure if we were rich, we could save my niece."

Others spoke unequivocally to the dangers of not being able to afford care. The 50-year-old Chagga man who lost his grandmother stated, "If you have no money you might die... if you don't have money to buy medication, you will die. What will save you is your pocket."

When healthcare costs became prohibitive, families had to negotiate for substandard care. For example, a 43-year-old Sambaa woman whose niece died of a fungal infection of the central nervous system reported: the doctor ... told us the medicines to treat that sickness were too expensive and amounted to 189,000 TZS [87.10 USD in 2016], but we were told there is an option: we could buy a half dose where every day we ... pay 27,000 TZS [12.44 USD in 2016]... When the patient completed the [half] dose the condition became worse.

Facilitators of receiving care. Proactive families. Most participants described either recognizing symptoms, proactively seeking care at health facilities when their family members were sick, or both. In one example, a 36-year-old Nyaturu man whose niece had died explained:

my parents advised us that she should be taken to a well equipped hospital whereby she can receive more tests. .. . The problem was that, she had cough and fever and sometimes difficulty breathing. This made me suspect that it could be a chest infection, which might be tuberculosis.

He goes on to describe how these symptoms led the patient's "mother and I . . to bring him to Kibong' oto hospital [the national tuberculosis hospital] and he was admitted there."

Another participant, a 66-year-old Chagga man described the urgency of seeking care for his sister-in-law when she developed a symptom of severe illness: "some people will tell you 'let's wait and see if the condition will improve,' but why should you wait while you see the person is in a coma already? Just take the patient to the hospital."

A different 66-year-old Chagga man, who lost his 15-yearold nephew, stated that they presented to a health facility because, "the child was sick and there was no way we could stay with him at home. We had to take him to the hospital ... because if you are living with someone who is sick you have to take them to the hospital."

Social capital. Although cost barriers were substantial at the individual level, many respondents reported successfully relying on family and friends to cover the cost of medical care. For many respondents, this financial assistance was instrumental when the deceased was sick. For example, the 67year-old Meru man whose niece died explained: "we know that there is cost sharing. ... Family members ... help and contribute some money for the sick family member, [and] the community is aware [of] that [phenomenon].

Another respondent, the 66-year-old Chagga man who lost his sister-in-law, described how his close relatives provided funds for an urgent diagnostic test: "money played a very important role, because for example when we were told about doing CT [computed tomography] scan, everybody looked at their M-pesa [mobile phone money service] account to find out how much money [they had] to contribute so the procedure can be done to save the life of the patient."

Another example came from the 43-year-old Sambaa aunt of the woman with a fungal infection of the central nervous system: "The doctor came in the ward and he said the patient had spinal fungus and we were asked to buy medicines which were very expensive. ... We didn't have money. We decided to start calling relatives, [and] those who had money sent it to us."

The 78-year-old Chagga man who had trouble paying ambulance fees for his son explained: "luckily [a] good neighbor 
gave [me] the money and [l] went back to the hospital to pay the charges and the patient was taken to KCMC." Other respondents described family members selling livestock to help pay for the cost of medical care. Overall, it was common-and often expected-for caregivers to turn to friends and family for financial support during a relative's illness.

\section{DISCUSSION}

The main themes that emerged from this study fell into two categories: 1) elaborations on known barriers to presenting to a health facility as well as barriers within the health system and 2) the emerging theme of facilitators of receiving care, which included proactive families and social capital. In this study, caregivers recognized symptoms that required medical care and proactively sought care. However, families bypassed local health facilities because of a perceived lack of staff or equipment and also faced transportation barriers in reaching health facilities. Healthcare system barriers stemmed mainly from a lack of referral patterns, leading to multiple facility visits during a given illness and self-referral behavior from families. Cost barriers were also clearly articulated. However, the impact of cost barriers appeared to be mediated by financial assistance accessed through participants' social networks, a phenomenon we conceptualize as a form of social capital.

Respondents in our study faced two main barriers to presenting to a health facility: a perceived lack of capacity of local health facilities and transportation barriers, such as distance or cost. Such barriers may have serious health impacts, as social biopsy work in the same setting found that a delay in presenting to care for a febrile illness was associated with an increased risk of mortality. ${ }^{11}$ Previous cross-sectional, uncontrolled studies in low-income countries suggested that delays in presenting to a health facility may be due to a lack of health literacy. ${ }^{19,20}$ However, a 2017 systematic review of social autopsy work found that recognition of severe illness was common but that care-seeking was not, suggesting that lack of health literacy is not to blame. ${ }^{10}$ In our study, an emerging theme was family members' proactive engagement with the healthcare system. This included triaging an illness to the appropriate level of care as well as health literacy for signs of severe febrile illness, as caregivers recognized WHO danger signs such as difficulty breathing and unconsciousness as indicating severe illness. ${ }^{1,3}$ Instead of health literacy being the problem, respondents reported not presenting to local health facilities because of a belief that these facilities had shortages of medicine or equipment, which we categorize as a perceived lack of capacity. Indeed, it has been documented that rural Tanzanian health facilities are often under-resourced to the point of impacting care. ${ }^{21,22}$ In light of these findings, families who experienced delays in presenting to care appear to be rational consumers of health care who are forced to compensate for an under-resourced and fragmented system. Therefore, an effective intervention to decrease delays in careseeking would be an investment in resources in first-level health facilities and strengthening of primary care medicine. However, although such decentralization is a common policy prescription, it is not a panacea and needs to be paired with a commitment to implementing best practices, such as the referral systems discussed in the following text.

Another important barrier to presenting to care is difficulty with transportation. Previous work in northern Tanzania demonstrated that taking $>1$ hours to reach a health facility significantly increased the odds of mortality during a febrile illness. ${ }^{11}$ However, that quantitative study could not elaborate on why participants experienced transport delays. In our qualitative study, respondents described several barriers that all related to the long distance of travel, including the cost of public transport, the inability of sick patients to tolerate long car rides, and the lack of a car. Previous social autopsy work has found transport to be a barrier to care ${ }^{9}$ including a 2015 study in Cameroon in which cost of transport emerged as a main barrier to formal care-seeking among newborns and their mothers. ${ }^{23}$ Transport barriers-and interventions to address them-need to be considered in the context of a given illness. Families are more likely to find solutions to transport barriers if the destination facility is perceived to provide quality care, if the patient is severely ill, or if the family has the social capital to access financial or transportation assistance from their social network. Therefore, although direct measures such as an increase in ambulances or an expansion of public transit may reduce barriers, an investment in rural health infrastructure to ensure families have confidence in their local health facility may not only reduce transport issues but also address other barriers identified in this study.

The general hospital referral structure in Tanzania is that health centers or dispensaries refer patients to district hospitals, and when an even higher level of care is needed, district hospitals refer to tertiary centers, such as KCMC and MRRH. However, we found inconsistencies in how facilities followed this pattern, causing families to either present to health centers multiple times before receiving the appropriate referral or to self-refer to a district or tertiary hospital. This is worrisome, as earlier quantitative work in the same setting has shown that each additional facility visit during a given illness was associated with increased odds of mortality. ${ }^{11}$ However, lowincome countries such as Tanzania often face infrastructural barriers that may preclude referrals. ${ }^{24}$ To address these challenges to referral, the WHO developed the Integrated Management of Childhood and Adolescent and Adult IIIness (IMCl/IMAI) handbooks to guide management of acute illness at remote health facilities. ${ }^{1,3}$ However, according to the IMCl/ IMAI, there are some severe signs-such as fever in infants up to 2 months of age or an inability to walk in an adult-that warrant urgent referral to a hospital, regardless of the structural barriers at play. In our study, it was clear that even these severe conditions did not always generate referrals. Therefore, although we recognize that barriers to referrals may exist in Tanzania, the referral system observed in this study appears to be contributing to the risk of death from febrile illness. One initial intervention may be to invest in a subset of health centers to turn them into "reference centers," specializing in coordination of an effective referral system, similar to the "Urban Health Project" achieved in Zambia in response to breakdowns in referral patterns similar to those observed in northern Tanzania. $^{25}$

An emerging theme in this study was families accessing financial assistance from family, friends, and neighbors to afford medical care. We categorize this phenomenon as an example of social capital. ${ }^{17,18}$ More specifically, financial assistance from family members can be described as bonding social capital-the interactions between people with a shared social identity-as opposed to bridging social capital, which refers to relations between people without a shared identity 
(e.g., voting in an election), or linking social capital, defined as relations across a power or authority gradient (e.g., healthcare-community partnerships). ${ }^{18}$ There is some debate as to the theoretical utility of social capital, as its definition varies widely and its role in mediating barriers to health care is ambiguous. $^{26,27}$ However, our data point to social capital mediating the effect of cost barriers, in concordance with previously published studies. The use of bonding social capital was not only common among those we interviewed but was also described matter-of-factly as an expected part of caring for a loved one. Although cost was described as a barrier to the treatment and survival of patients, social capital helped families overcome this obstacle. Formal health insurance schemes may also mediate the impact of the cost of care; however, as of 2015 , health insurance coverage in Tanzania was only $16 \% .^{28,29}$ In a previous study in northern Tanzania, researchers found no significant association between cost of care or lack of health insurance and mortality, despite hypotheses to the contrary. ${ }^{11}$ The finding from our study that social capital helps defray the cost of care may explain the lack of such an association. In line with our findings, a 2002 study of social capital in the Ivory Coast found that financial solidarity within social networks allowed access to health care that would otherwise have been prohibitively expensive. ${ }^{30}$ Similarly, quantitative studies of social capital in the United States have concluded that it is inversely related to barriers to health care ${ }^{31}$ and is directly associated with access to primary care. ${ }^{32}$ Thus, we conclude that social capital may be a useful explanatory variable alongside cost or health insurance in future research on barriers to care and that it warrants more study, especially in low-income countries.

This study had several limitations. First, transferability is limited, given that our sampling frame was limited to two health facilities in northern Tanzania. Furthermore, we did not interview anyone who survived their febrile illness, and those who died likely experienced more barriers to care. ${ }^{11}$ However, we were specifically interested in elaborating on the barriers found to be associated with mortality in our prior quantitative work, and our sampling frame therefore provided a higher density of data and more complete saturation of our themes. Second, credibility is limited, given that our results relied on only one type of qualitative data collection, namely in-depth interviews with families of deceased patients. We countered this to some extent by considering our results in the context of prior quantitative work that addressed similar themes. However, including key informant interviews with healthcare providers or participant observation in the healthcare setting would help triangulate themes and should be included in future studies.

Overall, this study was able to elaborate on the sociocultural and health systems barriers quantitatively associated with mortality in northern Tanzania. Although it is true that families delay seeking care outside the home, this does not appear to be due to a lack of health literacy but rather rational navigation of a health system that is under-resourced at first-level health facilities. Government investment in keeping first-level facilities fully stocked and properly staffed could therefore improve trust in health facilities and reduce time to seeking care. Furthermore, when patients do seek care at first-level facilities, there is a lack of formal referrals, increasing the risk of visiting multiple facilities and subsequently the risk of mortality. One intervention could be to upgrade a subset of health facilities to specialize in triage and referrals, as has been done in Zambia, to coordinate standardized referral patterns and avoid unnecessary self-referrals to district hospitals. Last, an emerging theme in our study was the importance of social capital in accessing health care. Social capital has been shown to increase access to health care in high-income countries, ${ }^{31,32}$ and it deserves further study in sub-Saharan Africa.

Received November 2, 2019. Accepted for publication March 15, 2020.

Published online April 20, 2020.

Note: Supplemental file appears at www.ajtmh.org.

Acknowledgment: We thank Paul Malimi for transcription and translation.

Financial support: U.S. National Institutes of Health, National Institute of Allergy, and Infectious Diseases through the Investigating Febrile Deaths in Tanzania (INDITe) grant (R01Al121378). C. M.'s effort was supported by a Diversity Supplement from the National Heart, Lung, and Blood Institute of the National Institutes of Health under grant U01HL142099-01S1.

Authors' addresses: Michael E. Snavely, Duke Global Health Institute, Duke University, Durham, NC, E-mail: michael.snavely@ucsf.edu. Martha Oshosen and Francis P. Karia, Kilimanjaro Christian Medical Centre, Moshi, Tanzania, E-mails: marthaoshoseny@gmail.com and frank2000tz@gmail.com. Elizabeth F. Msoka, Blandina T. Mmbaga, and Venance P. Maro, Kilimanjaro Christian Medical University College, Moshi, Tanzania, E-mails: e.fbright@kcri.ac.tz, blaymt@ gmail.com, and venmaro@ymail.com. Michael J. Maze and John A. Crump, Centre for International Health, University of Otago, Dunedin, New Zealand, E-mails: michael.maze@otago.ac.nz and john.crump@ otago.ac.nz. Lauren S. Blum, Consultant, Duke University, Durham, NC, E-mail: laurensblum@yahoo.com. Matthew P. Rubach, Division of Infectious Diseases and International Health, Duke University Medical Center, Durham, NC, E-mail: matthew.rubach@duke.edu. Charles Muiruri, Department of Population Health, Duke University, Durham, NC, E-mail: muiru001@duke.edu.

\section{REFERENCES}

1. World Health Organization, 2014. IMCl Chart Booklet. World Health Organization. Available at: http://www.who.int/maternal_child_ adolescent/documents/IMCl_chartbooklet/en/. Accessed January $3,2017$.

2. Jones G, Steketee RW, Black RE, Bhutta ZA, Morris SS, Bellagio Child Survival Study Group, 2003. How many child deaths can we prevent this year? Lancet 362: 65-71.

3. World Health Organization Department of HIV, 2005. Integrated Management of Adolescent and Adult IIIness: Interim Guidelines for First-Level Facility Health Workers at Health Centre and District Outpatient Clinic. WHO. Available at: http://www.who.int/ hiv/pub/imai/en/acutecarerev2_e.pdf. Accessed January 3, 2017.

4. Wang Het al., 2016. Global, regional, and national life expectancy, all-cause mortality, and cause-specific mortality for 249 causes of death, 1980-2015: a systematic analysis for the Global Burden of Disease Study 2015. Lancet 388: 1459-1544.

5. Institute for Health Metrics and Evaluation (IHME), 2016. GBD Compare Data Visualization. Seattle, WA: IHME, University of Washington. Available at: http://vizhub.healthdata.org/gbdcompare. Accessed October 24, 2016.

6. Hildenwall H, Tomson G, Kaija J, Pariyo G, Peterson S, 2008. "I never had the money for blood testing" - caretakers' experiences of care-seeking for fatal childhood fevers in rural Uganda a mixed methods study. BMC Int Health Hum Rights 8: 12.

7. Källander K, Hildenwall H, Waiswa P, Galiwango E, Peterson S, Pariyo G, 2008. Delayed care seeking for fatal pneumonia in children aged under five years in Uganda: a case-series study. Bull World Health Organ 86: 332-338.

8. de Savigny D, Mayombana C, Mwageni E, Masanja H, Minhaj A, Mkilindi Y, Mbuya C, Reid HKG, 2004. Care-seeking patterns for fatal malaria in Tanzania. Malar J 3: 27. 
9. Kalter HD, Salgado R, Babille M, Koffi AK, Black RE, 2011. Social autopsy for maternal and child deaths: a comprehensive literature review to examine the concept and the development of the method. Popul Health Metr 9: 45.

10. Moyer CA, Johnson C, Kaselitz E, Aborigo R, 2017. Using social autopsy to understand maternal, newborn, and child mortality in low-resource settings: a systematic review of the literature. Glob Health Action 10: 1413917.

11. Snavely ME et al., 2018. Sociocultural and health system factors associated with mortality among febrile inpatients in Tanzania: a prospective social biopsy cohort study. BMJ Glob Health 3: e000507.

12. Gibson $\mathrm{CB}, 2017$. Elaboration, generalization, triangulation, and interpretation. Organ Res Methods 20: 193-223.

13. Foss $C$, Ellefsen $B, 2002$. The value of combining qualitative and quantitative approaches in nursing research by means of method triangulation. J Adv Nurs 40: 242-248.

14. Brown $\mathrm{K}$ et al., 2016. Mixed-methods study identifies key strategies for improving infant and young child feeding practices in a highly stunted rural indigenous population in Guatemala. Matern Child Nutr 12: 262-277.

15. Barbour RS, 1999. The case for combining qualitative and quantitative approaches in health services research. $J$ Health Serv Res Policy 4: 39-43.

16. Maluka S, Chitama D, 2017. Primary Health Care Systems (Primasys): Comprehensive Case Study from United Republic of Tanzania. Geneva, Switzerland: Available at: https://www.who.int/alliancehpsr/projects/AHPSR-PRIMASYS-Tanzania-comprehensive.pdf? ua=1. Accessed September 14, 2019.

17. Berkman LF, Kawachi I, Glymour MM, 2014. Social Epidemiology, 2 edition. Oxford, United Kingdom: Oxford University Press. Available at: https://global.oup.com/academic/product/socialepidemiology-9780199395330?cc=us\&lang=en\&\#. Accessed September 14, 2019.

18. Derose KP, Varda DM, 2009. Social capital and health care access: a systematic review. Med Care Res Rev 66: 272-306.

19. Hill Z, Kendall C, Arthur P, Kirkwood B, Adjei E, 2003. Recognizing childhood illnesses and their traditional explanations: exploring options for care-seeking interventions in the context of the IMCl strategy in rural Ghana. Trop Med Int Health 8: 668-676.

20. Sreeramareddy CT, Shankar RP, Sreekumaran BV, Subba SH, Joshi HS, Ramachandran U, 2006. Care seeking behaviour for childhood illness- a questionnaire survey in western Nepal. BMC Int Health Hum Rights 6: 7.

21. Penfold S, Shamba D, Hanson C, Jaribu J, Manzi F, Marchant T, Tanner M, Ramsey K, Schellenberg D, Schellenberg JA, 2013. taff experiences of providing maternity services in rural southern Tanzania - a focus on equipment, drug and supply issues. BMC Health Serv Res 13: 61.

22. Tanzania Ministry of Health and Social Welfare, 2008. In-Depth Assessment of the Medicines Supply System in Tanzania. Dar es Salaam, Tanzania: Ministry of Health and Social Welfare.

23. Koffi AK, Libite P-R, Moluh S, Wounang R, Kalter HD, 2015. Social autopsy study identifies determinants of neonatal mortality in Doume, Nguelemendouka and Abong-Mbang health districts, Eastern Region of Cameroon. J Glob Health 5: 010413.

24. Lambrechts T, Bryce J, Orinda V, 1999. Integrated management of childhood illness: a summary of first experiences. Bull World Health Organ 77: 582-594.

25. Atkinson S, Ngwengwe A, Macwan'gi M, Ngulube TJ, Harpham T, O'Connell A, 1999. The referral process and urban health care in sub-Saharan Africa: the case of Lusaka, Zambia. Soc Sci Med 49: $27-38$.

26. Leeder S, Dominello A, 1999. Social capital and its relevance to health and family policy. Aust N Z J Public Health 23: 424-429.

27. Labonte $R, 1999$. Social capital and community development: practitioner emptor. Aust N Z J Public Health 23: 430-433.

28. Amu H, Dickson KS, Kumi-Kyereme A, Kofuor E, Darteh M, 2018. Understanding variations in health insurance coverage in Ghana, Kenya, Nigeria, and Tanzania: evidence from demographic and health surveys. PLoS One 13: e0201833.

29. Dutta A, 2015. Prospects for Sustainable Health Financing in Tanzania: Baseline Report. Washington, DC: Available at: https://www.healthpolicyproject.com/pubs/788_Prospe ctsforSustainableHealthFinanciFINAL.pdf.

30. Ayé M, Champagne F, Contandriopoulos A-P, 2002. Economic role of solidarity and social capital in accessing modern health care services in the Ivory Coast. Soc Sci Med 55: 1929-1946.

31. Perry M, Williams RL, Wallerstein N, Waitzkin H, 2008. Social capital and health care experiences among low-income individuals. Am J Public Health 98: 330-336.

32. Prentice JC, 2006. Neighborhood effects on primary care access in Los Angeles. Soc Sci Med 62: 1291-1303. 